\title{
La efectividad del uso del miedo como factor persuasivo en la comunicación de riesgos en las crisis sanitarias
}

\author{
Roberto Rodríguez Andrés \\ (Madrid, España) \\ Universidad de Navarra. Universidad Pontificia de Comillas-ICADE
}

\section{Palabras clave \\ comunicación de crisis comunicación y salud comunicación de riesgos miedo persuasión}

\begin{abstract}
Resumen
Cuando se produce una crisis sanitaria, las administraciones deben comunicar a los ciudadanos los riesgos a los que se van a ver expuestos. Esta 'comunicación de riesgos' se basa en la difusión de mensajes que ayuden a la población a conocer los orígenes de la crisis, las amenazas, el nivel de alerta y las medidas a adoptar para minimizar los daños, y se basa frecuentemente en las apelaciones al miedo como factor persuasivo a través del cual convencer a la población de que actúe como se le demanda. En el presente artículo se analizan las investigaciones sobre el impacto que estas apelaciones al miedo tienen sobre la población, proponiendo una serie de recomendaciones que permiten que estos mensajes tengan la máxima eficacia, contribuyendo así a una mejor gestión de la crisis sanitaria
\end{abstract}




\section{The Effectiveness of the Use of Fear as a Persuasive Factor in Risk Communications During Health Crises}

\begin{tabular}{c}
\hline Keywords \\
\hline crisis communication \\
health communication \\
risk communication \\
fear \\
persuasion
\end{tabular}

Cómo citar el artículo

Rodríguez Andrés, R. (2011). La efectividad del uso del miedo como factor persuasivo en la comunicación de riesgos en las crisis sanitarias. Revista de Comunicación y Salud, 1(2), pp. 33-46.

DOI: http://doi.org/10.35669/revistadecomunicacionysalud.2011.1(2).33-46

En el ámbito de la comunicación, se suele decir que hay dos tipos de organizaciones: las que han pasado ya una crisis y aquellas que la pasarán en el futuro (Alcat, 2005). La aparición de crisis con repercusión informativa y, por tanto, la necesidad de gestionar comunicación en tiempos de crisis, es algo consustancial a la actividad de las organizaciones y por eso es tan importante saber cómo actuar en estos casos y disponer de una buena infraestructura comunicativa que contribuya a paliar los posibles daños que pueden generar en el ámbito de la opinión pública. Porque una crisis puede acabar con la reputación de una empresa o de una institución, aunque también es verdad que una crisis bien gestionada puede aumentar su credibilidad e imagen.

Siendo esto importante en cualquier sector, uno de los más susceptibles a estas situaciones es el sanitario. En primer lugar, por la naturaleza de lo que está en juego: la salud e, incluso, la vida, que son consideradas por la inmensa mayoría de los ciudadanos como lo más importante. Un medicamento defectuoso, una epidemia, una intoxicación alimentaria, una vacuna 
en mal estado... son circunstancias que pueden provocar serios daños en la salud individual o colectiva. Y, en segundo lugar, porque los periodistas conceden cada vez más relevancia a la información sobre salud, unido al hecho de que, por la propia idiosincrasia de los medios, las noticias sobre crisis, riesgos y posibles peligros para la población son de gran interés e impacto informativo (Altheide, 2002; Rodríguez Andrés y Ureña, 2008).

Mucho se ha hablado y escrito sobre la gestión de la comunicación en casos de crisis, sobre todo en el ámbito empresarial (González Herrero, 1998; López-Quesada, 2003; Alcat, 2005, 2009; Marín, 2009; Losada, 2010) pero también en el sector sanitario (Martínez Solana, 2004; Saura, 2005; Seeger y Sellnow, 2007). En el presente trabajo nos centraremos en uno de los aspectos que más controversia suele generar. Nos referimos a la efectividad del uso del miedo como recurso persuasivo para tratar de convencer a la opinión pública de que debe seguir las pautas de comportamiento indicadas si no quiere padecer las consecuencias de la amenaza, un análisis vinculado a lo que se ha denominado en el ámbito académico como `comunicación de riesgos'.

Y si utilizamos el término 'controversia' es porque, con frecuencia, los medios e incluso los propios políticos (sobre todo cuando están en la oposición) suelen emplear un doble rasero. Por un lado, si las administraciones hacen llamamientos a la calma, se les acusa de estar queriendo esconder los peligros y de actuar con intereses electoralistas. Pero, a la vez, si hacen advertencias a la población a veces se les acusa de crear alarma, de generar una preocupación innecesaria o desmedida, de producir estados de emergencia e incertidumbre que paralizan a la gente y les ocasionan ansiedad.

\section{Cuestiones previas sobre la comunicación de las crisis sanitarias}

Precisamente por esto, desde el punto de vista de la comunicación una de las cosas más difíciles de calibrar es cuándo comunicar un posible riesgo sanitario a la opinión pública y la intensidad con la que trasladar los mensajes, buscando el binomio de alertar cuando es preciso pero sin alarmar o despertar un miedo innecesario.

Lo que parece claro, en opinión de los expertos en comunicación de crisis, es que no se puede mentir ni ocultar una alerta. Para Alcat, "el silencio no es rentable" (2005: 28) y Arroyo y Yus dicen que "no comunicar los riesgos para no asustar" es uno de los mayores errores que se pueden cometer (2007: 131). En el mismo sentido, Acinas apunta también que "para controlar el riesgo primero hay que darlo a conocer" (2007: 91). Callar en estos casos es un error pero, además, una irresponsabilidad que puede conllevar numerosos riesgos y también un incumplimiento de la obligación legal que tienen las administraciones de mantener informada a la población en este tipo de sucesos.

Es evidente, como defiende Martínez Segura (2006), que en los sistemas democráticos con libertad de prensa esta ocultación, aunque se intentara por parte de los políticos, no tendría efecto porque la crisis acabaría siendo difundida por los medios y los ciudadanos castigarían fuertemente a quienes les han tenido engañados. En cambio, donde sí pueden seguir dándose 
estas prácticas es en aquellos países con censura o fuerte control sobre los periodistas. China, por ejemplo, ocultó a la OMS y a su propia población durante varios meses la dimensión real que tenía el brote de neumonía asiática y el de la gripe aviar.

Pero asumiendo que mentir u ocultar la alarma no es lo más recomendable, la disyuntiva que se plantea es qué nivel de alerta emplear o, dicho de otro modo, y a los efectos del presente artículo, cuánto miedo despertar entre la población en la comunicación del riesgo. A veces, muchos políticos, por querer minimizar el problema, acaban minimizando también los riesgos. Queda en el recuerdo la célebre frase del ministro de Sanidad español Sancho Rof en la crisis del aceite de colza, a inicios de los 80 del siglo pasado, cuando dijo para tranquilizar a la población que el origen del mal era "un bichito tan pequeño que si se cae de la mesa, se mata". En estos casos, se suele aludir a que nunca se debe minimizar o dar por solucionado un problema cuando realmente no lo está.

Pero, por otro lado, hay también casos en los que se fomenta un nivel de alarma excesivo, como se criticó por ejemplo en la gestión de la pandemia de gripe A por parte de la Organización Mundial de la Salud (OMS). En este caso, además, se dio la coincidencia de que se criticó también la posible connivencia de este organismo con los laboratorios farmacéuticos, con lo que la alarma generada fue aún peor vista y más criticada por los medios.

En función de lo apuntado, se podría decir que determinar la intensidad con que se comunica la alerta es uno de los retos más complicados a los que se enfrenta una institución. Y el otro, sin duda, tiene que ver con que cuando surge una crisis sanitaria, y más si es de amplio espectro, el miedo es el primer factor que entra en escena. Miedo a ser contagiado por algún virus, a contraer una enfermedad, incluso a perder la vida... El miedo, por tanto, es un factor emocional que está presente en la gestión de las crisis sanitarias y quienes se enfrentan a ellas deben ser conscientes de que su trabajo va a estar condicionado por este hecho, con las dificultades que conlleva.

En estos casos el miedo es libre y la población, llevada por la incertidumbre y la desconfianza, suele tomar posturas extremas que le alejen de cualquier riesgo. Impera aquí la denominada "percepción selectiva", que hace que los ciudadanos se queden con la información negativa o con los posibles peligros antes que con las soluciones a adoptar para frenarlos. En palabras de Alcat, "el que escucha tiende a interpretar lo que oye de una forma más exagerada y alarmista en un caso de crisis" (2005: 61). En medio de la crisis de las "vacas locas", por ejemplo, el consumo de carne de vacuno se desplomó, por mucho que las administraciones intentaran trasladar que se estaban haciendo todos los controles y que no había ningún riesgo de ingerir los productos disponibles en el mercado. Lo mismo ocurrió con los pepinos en el brote de e.coli que afectó a Alemania en junio de 2011 y, cuando saltó la gripe aviar, con la carne de pollo. En este último caso se vio un ejemplo claro de cómo el miedo funciona la mayor parte de las veces de forma completamente irracional, puesto que se había insistido en que el virus no se contraía a través de la ingesta sino por el contacto con los animales y, más aún, porque esa bajada de consumo se vio acompañada de una fuerte subida de los productos derivados del pavo, cuando la gripe aviar podía también afectar a estos animales. El hecho de que esta gripe fuera conocida popularmente como "gripe del pollo" estaba detrás de esta incongruencia. 
La evidencia de que el miedo, como factor netamente emocional, se comporta a veces fuera de las reglas de la lógica hace que las organizaciones tengan que estar técnicamente preparadas para poder afrontar la avalancha de información que se puede generar. Hay que dar respuesta a la gente que puede estar demandando noticias llevada por el miedo, activando teléfonos de atención al ciudadano, manteniendo actualizada la página web, lanzando campañas de publicidad y, en los momentos actuales, contando con la importancia que las redes sociales pueden tener también en la difusión de mensajes.

\section{El miedo como factor persuasivo}

Pero en casos de crisis sanitarias, el miedo no sólo forma parte de la reacción emocional de la población, sino que puede ser empleado también por las administraciones para alertarla de los riesgos a los que está expuesta. El miedo puede hacer precisamente que los ciudadanos se muestren más receptivos a las recomendaciones que se les lanza para evitar el posible daño.

En este contexto, se ha constatado que las apelaciones al miedo en la comunicación de riesgos son muy efectivas para condicionar las opiniones y los comportamientos, siendo así un importante factor de influencia. Como afirma Gordon (1971), el secreto de este poder reside en que actúa de forma directa sobre los sentimientos y lo emocional, que tanta repercusión tienen en el ser humano. Quizá por este motivo ha sido tan frecuentemente utilizado ya que, como sostienen Pratkanis y Aronson (1994: 216), "valerse del miedo es un recurso sumamente eficaz". Esto ha llevado a que numerosos autores a lo largo del tiempo hayan considerado el recurso al miedo como una "herramienta persuasiva" más (Boster y Mongeau, 1984; Stiff, 1994; Mongeau, 1998; Collins, 2009).

En el terreno de la comunicación, especialmente en el ámbito publicitario, se vienen realizando desde mediados del siglo pasado numerosas investigaciones acerca de la influencia que tienen los mensajes que utilizan el miedo o la alarma en campañas de promoción de la salud, como las dirigidas a disminuir el consumo de alcohol, tabaco u otras drogas o las encaminadas a luchar contra el SIDA o los accidentes de tráfico. Estos trabajos coinciden a la hora de dotar a este tipo de apelaciones de un poder cierto sobre los seres humanos, pero a pesar de este consenso acerca de su fuerza movilizadora, donde no se ha conseguido un acuerdo es a la hora de determinar qué dosis de miedo son más efectivas, llegando a producirse respuestas divergentes (Higbee, 1969; Leventhal, 1970; Sutton, 1982; Dillard, 1994; Mongeau, 1998; Dillard y Anderson, 2004; Argo y Main, 2004; Cho y Witte, 2004). Como afirma Rotfeld (1988), parece como si la comunidad investigadora se hubiera embarcado en una permanente búsqueda del "nivel óptimo de miedo" que hace más persuasivos los mensajes, sin que hasta el momento se haya encontrado la ansiada respuesta.

A primera vista podría pensarse que cuanto mayor sea el temor generado, más efecto tendrá éste en el receptor (Sternthal y Craig, 1974; Beck y Davis, 1978; Sutton, 1982; Salcedo, 2008). Sin embargo, otros consideran que ésta no es la vía más efectiva para lograr que el mensaje sea más persuasivo. Así lo cree Janis, que comprobó que aquellos individuos sujetos a men- 
sajes más amenazantes se veían menos persuadidos a adoptar una nueva conducta que aquellos otros que habían sido expuestos a mensajes más débiles y ello porque, al parecer, se produce una huida por parte del receptor ante aquellos estímulos que intentan atemorizarle en exceso (Janis y Feshbach, 1953; Hovland, Janis y Kelley, 1953; Janis, 1967).

Este mismo modelo fue aplicado años después por McGuire, cuyos trabajos sobre actitudes y cambios de comportamiento concluyen que la solución se encuentra en el término medio. Aquellos mensajes con apelaciones de temor leves apenas tendrán efecto y aquellos otros en los que estas apelaciones sean extremas provocarán rechazo entre los receptores (McGuire, 1964, 1968, 1969, 1973).

\section{Recomendaciones para aumentar la efectividad persuasiva de los mensajes de riesgo con apelaciones al miedo}

Para resolver esta aparente contradicción, otros trabajos han optado por vías conciliadoras. De esta forma, a lo largo del tiempo se han propuesto tres modelos en los que se han ido encuadrando los diferentes estudios que se han realizado. El primero de ellos (Paralell Response Model) fue formulado a inicios de los 70 por Leventhal (1970). El segundo (Protection Motivation Theory) partió de las tesis expuestas por Rogers en 1975 (Rogers, 1975, 1983, 1985; Rogers y Prentice-Dunn, 1997). Y el tercero, el más cercano en el tiempo, y denominado Extended Paralell Process Model, es un desarrollo del modelo planteado por Leventhal en el que se recogen en buena medida las aportaciones realizadas también por Rogers. Este modelo de síntesis fue descrito en los años 90 por Witte y, hasta el momento, es considerado como el más completo a la hora de explicar los efectos que tienen las apelaciones al miedo en las actitudes y comportamientos del ser humano (Witte, 1992, 1994, 1998; Witte y Allen, 2000).

Lo común a estos enfoques es que no han intentado centrarse tanto en la medición de cuál es la dosis exacta de miedo más efectiva, como habían hecho los estudios precedentes, sino en determinar cuáles son los factores que hacen que una apelación de esta naturaleza funcione en mayor o menor medida. $Y$ en el marco de estas investigaciones, se pueden proponer las siguientes recomendaciones:

\subsection{Se deben evaluar detenidamente los riesgos para calibrar la intensidad de los men- sajes}

Lo primero que debe hacerse ante una situación de crisis es evaluar detenidamente los riesgos reales, tanto actuales como futuros, porque los mensajes que se lancen y las actuaciones que se adopten deberán adecuarse a esa información, así como la graduación del nivel de alerta que se quiera trasladar a la población.

En abril de 2008, el Ministerio de Sanidad español fue criticado por no haber tenido en cuenta este principio en la gestión de la crisis del aceite de girasol por una partida contaminada procedente de Ucrania. El Ministerio tomó la decisión de retirar del mercado todas las botellas y 
recomendó a la población no consumir el que tuviera en casa. Sin embargo, el mensaje oficial decía que no había riesgos para la salud, puesto que se trataba de dosis contaminantes ínfimas, y por otro lado tardó más de 48 horas en concretar qué marcas de aceite estaban implicadas. Esta falta de claridad hizo que tuviera que afrontar duras críticas por parte de la oposición y también de los medios, al acusarle de haber actuado de forma precipitada, desproporcionada y sin medir la alarma social que estaba generando. Hay que recordar, además, que España fue el único país de la UE que adoptó una posición tan extrema como la retirada de todo el aceite.

En este mismo ámbito, es evidente que la evaluación de los posibles riesgos que se hace al inicio de una crisis puede variar según ésta vaya avanzando. Por eso es importante que se evalúe el alcance que están teniendo los mensajes lanzados, sobre todo para saber si la población los está comprendiendo correctamente.

\subsection{Conocer a la audiencia es el paso previo al diseño de los mensajes}

En líneas generales, en tiempos de crisis los riesgos deben ser comunicados en mensajes claros, fácilmente comprensibles, que apelen no sólo a la razón sino también a la emoción y que no den lugar a dudas o ambigüedades, para lo que se debe proporcionar formación específica a quienes vayan a actuar como portavoces. Pero, además de esto, y para garantizar la máxima persuasibilidad, hay un consenso generalizado acerca de la importancia de conocer lo mejor posible a la audiencia para adecuar específicamente los mensajes a sus características, ya que no todos los seres humanos comparten la misma personalidad y la misma predisposición a ser influidos o afectados por este tipo de apelaciones. Además, hay que tener claro, como apunta Valera (2008: 51), que en crisis "nunca se debe transmitir lo que uno quiere decir sino lo que la gente quiere escuchar" y para eso hay que conocer bien a los receptores.

Por ejemplo, parece haberse comprobado que aquellos que tienen un estado de ánimo más relajado son más proclives a responder a las apelaciones al miedo que los que se encuentran bajo situaciones de nerviosismo o estrés (Hovland, Janis y Kelley, 1953; Burgoon, Jones y Stewart, 1975). Quizá este factor explique, por ejemplo, la reacción de los ciudadanos japoneses ante la posible contaminación nuclear de los alimentos tras la fuga de Fukushima en 2011. La serenidad milenaria de este pueblo se puso de manifiesto en esta crisis, contribuyendo a rebajar el nivel de alarma y a que el consumo de alimentos o de agua del grifo no experimentara unos descensos drásticos que quizás sí se hubieran producido en sociedades más "pasionales", como por ejemplo la española.

También influyen características personales como el sexo, el nivel de estudios, la experiencia previa con este tipo de apelaciones, las tradiciones culturales o la situación socio-económica de los individuos, aunque en este punto las conclusiones no siempre son coincidentes. Baylon y Mignot (1996) apuntan, por ejemplo, que las apelaciones al miedo son más efectivas entre los más jóvenes. Otros, como Boster y Mongeau (1984), sugieren lo contrario, es decir, que tienen más impacto entre la gente mayor. 
Se ha destacado igualmente que, en contra de lo que pudiera parecer, el hecho de que la sociedad tenga cada vez más información en temas de salud no está contribuyendo a que afronten las crisis sanitarias de una forma más racional. Al contrario, como se puso de manifiesto en una encuesta realizada por la revista Atención Primaria, esta cantidad de información ha provocado actitudes de ansiedad e hipocondría que aumentan también el temor (Cebrià Andreu et al., 2005).

Lo que sí parece evidente, a la vista de la experiencia de las últimas crisis sanitarias, es que el nivel de alarma es mucho mayor cuando se trata de cuestiones que afectan a la infancia, que generan gran desasosiego entre las familias, tal como se vio en el caso del brote de meningitis $C$ de Madrid o cada vez que se detectan partidas de leche infantil contaminadas.

\subsection{La amenaza debe sentirse como próxima o cercana para que haya más persuasión}

Por muy intensa que fuera la apelación al miedo no sería efectiva si la amenaza no fuera sentida como cercana y, por tanto, como algo que puede afectar personalmente y en cualquier momento a quien está expuesto a ella. Como ya apuntó Aristóteles en su Retórica (ed. 1985: 107) "lo que está muy lejos no se teme, pues todos saben que morirán, pero como no está cerca no se preocupan". Por este motivo, las apelaciones al miedo son mucho más impactantes cuando se muestran como próximas, intentando que en el subconsciente del que las escucha no se activen razonamientos del tipo "esto no me puede suceder nunca a mí". Precisamente pensamientos como estos han motivado investigaciones acerca, por ejemplo, de cómo hacer más efectivas las campañas de promoción de la salud entre los jóvenes, que suelen pensar que el riesgo de padecer enfermedades como consecuencia del consumo de drogas, tabaco o alcohol es algo muy lejano y que no les afecta y, por tanto, los mensajes tienen menos efectividad entre ellos (Henley y Donovan, 2003).

\subsection{La credibilidad de la fuente es fundamental}

La fuente que emite el mensaje debe ser creíble a ojos de la audiencia porque si no lo es, no se tendrá en cuenta lo que dice o se subestimará la amenaza. En este sentido, se ha comprobado cómo la eficacia de un mismo mensaje es mucho mayor si quien lo expone es un médico en vez de un político. Y ello porque los ciudadanos conceden al profesional sanitario mayor experiencia en este ámbito y, por tanto, mayor credibilidad a la hora de explicar la potencial amenaza o las recomendaciones para evitarla (Hewgill y Millar, 1965; Hansen y Scout, 1976; Sternthal, Phillips y Dholakia, 1978; Wiener y Mowen, 1986).

Relacionado con este factor de credibilidad, también es muy importante evitar la doble moral, es decir, que la fuente de los mensajes sea consecuente con lo que está trasladando a la población, dando así una imagen de ejemplaridad. Corría el año 1997 cuando en España se vivió un caso muy significativo de quiebra de este principio. Ante la aparición del brote epidémico de meningitis $C$ en Madrid antes mencionado, y la gran alarma social que se desató, el Gobierno sostuvo como mensaje oficial que no había que tomar ninguna medida extraordinaria, 
haciendo un llamamiento a la calma. Sin embargo, el periódico Diario 16 sacó a la luz en esas fechas (26/02/1997), con la consecuente polémica, que el presidente del Congreso, Federico Trillo, había enviado su coche oficial a recoger vacunas para sus hijos.

Para intentar ganar en credibilidad y, a la vez, infundir calma a la población y paliar el miedo, es muy socorrido el poner en marcha "simulacros" que muestren las medidas que se han adoptado para controlar los riesgos y también el uso de "imágenes ejemplarizantes", en las que se ve a los políticos llevando a cabo acciones sobre las que la población tiene desconfianza. Un ejemplo de esta situación se dio durante la crisis de las "vacas locas", cuando fue muy común que los políticos aparecieran ante las cámaras consumiendo carne de vaca, intentando así dar una imagen de confianza a la población de que podían hacer lo mismo sin ningún riesgo.

Un último punto que ha de ser considerado en torno a la credibilidad de la fuente tiene que ver con que, si se recurre en exceso a los mensajes amenazantes, se puede provocar un efecto similar al del cuento del lobo. Si se alarma innecesariamente a la población ante cualquier problema, llegará el día en el que, ante una alarma real, la gente ya no escuche los mensajes o tienda a desconfiar de ellos.

\subsection{Incluir una recomendación clara y sin contradicciones para evitar el daño aumenta la persuasión}

Con respecto a la forma en la que el ser humano afronta racionalmente todo este proceso, es también muy efectivo que el mensaje atemorizador venga acompañado de una recomendación concreta para superar la amenaza. Y es que ofrecer al receptor una vía de escape a través de la cual superar el miedo es uno de los factores que más influencia tienen sobre sus actitudes y comportamientos. Por eso es tan importante que las recomendaciones y respuestas que dan los gobiernos sean claras y sin contradicciones, porque éstas, cuando se producen, hacen aumentar el nivel de temor y desconcierto entre la población.

Pero a todo esto se añadiría otro punto más, que consiste en que el impacto positivo de la recomendación aumenta si ésta se percibe como realmente eficaz para solucionar el daño y, sobre todo, fácil de aplicar. Esto es lo que lleva a Witte (1998) a concluir que cuando la eficacia de la recomendación es alta y, además, se presenta como sencilla de acometer, el proceso racional logra imponerse al emocional, haciendo que el ser humano se sobreponga al miedo y acepte lo que se le propone, aumentando así la fuerza persuasiva del mensaje. Por el contrario, cuando la amenaza es de gran intensidad y el receptor percibe que las recomendaciones que se le dan no son eficaces o son muy difíciles de llevar a cabo, predominará la vía irracional, provocando la ansiedad, la multiplicación del miedo y el desconcierto ante la falta de salidas.

Por eso, en este contexto lo peor que puede ocurrir es que no se pueda ofrecer ninguna recomendación porque se desconozca el origen de la crisis y, por tanto, la forma de evitar el riesgo. Esto sucedió en España con la crisis de la colza, en la que se tardaron varios meses en identificar el agente causante mientras aumentaba día a día el número de afectados e incluso de muertos. Y también algo similar se produjo con el brote de e.coli en Alemania. En este caso, 
la administración fue apuntando posibles orígenes (el primero de ellos, los pepinos españoles) que eran desmentidos con análisis posteriores, generando desconfianza y alarma, además de numerosas pérdidas económicas al sector agrícola. Este desconcierto a la hora de comunicar las causas del brote llevó incluso a la Comisión Europea a pedir a Alemania que no siguiera lanzando hipótesis sin base científica clara.

\subsection{Llevar la iniciativa y frenar los rumores}

Por último, hay que tener en cuenta que en una situación de crisis aumenta el número de fuentes que pueden trasladar mensajes a la población, lo que puede conllevar multiplicidad de mensajes y de posibles focos de contradicción que, como se ha expuesto, hacen aumentar el temor. Por eso es muy importante saber que si no eres tú quien da la información, otro lo hará por ti, porque hay mucha demanda de noticias en esos momentos de crisis. Hay que informar de forma periódica para que tanto periodistas como opinión pública vayan viendo cómo evoluciona la situación, de forma proactiva y sin ocultismos. Como afirma Valera (2008: 51), "la mejor forma de gestionar la inclinación de los medios a fomentar el miedo es comunicar eficaz e ininterrumpidamente".

Además, en estos casos, dominados por la irracionalidad del miedo, aumentan los rumores y las informaciones confusas, que contribuyen a generar más miedo. Es muy necesario controlar esto desde el primer momento (y muy especialmente hoy día con el auge de internet y las redes sociales, donde una información puede expandirse a gran velocidad). Como explica Marín (2005), en este tipo de situaciones a veces tiene más impacto el boca a boca, casi siempre por vía de rumores, que la información oficial, haciendo que un alto porcentaje de la población se entere antes de lo sucedido por otros.

\section{Una última consideración ética sobre el uso del miedo en la comunicación de riesgos en crisis sanitarias}

Como criterio general, y tal como se ha ido exponiendo a lo largo del presente artículo, las administraciones deben actuar siempre bajo el criterio de alertar a la población de los riesgos a los que puede estar expuesta pero, a la vez, intentando evitar alarmas innecesarias. En este marco, el recurso al miedo debe ser empleado solo en las circunstancias que realmente lo requieran. A este respecto, resulta reveladora la distinción que efectúan Pratkanis y Aronson. Según estos autores, "si decidimos recurrir al expediente de suscitar temor, tenemos la obligación de asegurarnos de que ese temor es, por lo menos, legítimo y de que además sirve para alertar al grupo objetivo o destinatario de los peligros latentes, en vez de enmascarar el tema con argumentos de índole emocional" (1994: 223).

En estos casos, el empleo del miedo se hace desde una perspectiva racional, exponiendo argumentos basados en evidencias y sin recurrir a factores irracionales. Sin embargo, como afirma López Quintás, el recurso del miedo puede emplearse también cuando lo que se quiere es que los ciudadanos no afronten los problemas de modo racional, sereno, concienzudo, sino 
llevados exclusivamente por las emociones, por lo irracional, por el temor (1998: 225).

Y en este debate se debe apelar también a la función social de los medios de comunicación, que deben actuar con la máxima profesionalidad, siendo rigurosos y no dejándose llevar por rumores o informaciones no contrastadas que, casi siempre, contribuyen aún más a elevar los niveles de preocupación entre los ciudadanos. Y, al mismo tiempo, deben alertar sobre un uso injustificado o irracional del miedo por parte de los gobiernos cuando lo que pretenden es tapar con esas apelaciones la verdadera naturaleza de los problemas, ocultar otras informaciones o servir a intereses particulares en vez de colectivos.

\section{Referencias}

Acinas, M. P. (2007). Gestión de la información y mensajes a la población en situaciones de emergencia, evacuaciones y simulacros. Emergencias. № 19, pp. 88-95.

Alcat, Enrique (2005). Y ahora ¿qué?: cómo gestionar una crisis y salir fortalecido. Barcelona: Empresa Activa.

Alcat, Enrique (2009). Seis recetas para superar la crisis. Barcelona: Alienta.

Altheide, D. (2002). Creating fear: news and the construction of crisis. Nueva York: Aldine Gruyter.

Aristóteles (1985). Retórica. Madrid: Centros de Estudios Constitucionales.

Argo, Jennifer J. y Main, Kelley J. (2004). Meta-analysis of the effectiveness of warning labels. Journal of Public Policy \& Marketing. Vol. 23, $n^{\circ}$ 2, pp. 193-208. doi: 10.1509/jppm.23.2.193.51400

Arroyo, Luis y Yus, Magali (2007). Los cien errores de la comunicación de las organizaciones. Madrid: ESIC.

Baylon, Christian y Mignot, Xavier (1996). La comunicacion. Madrid: Cátedra.

Beck, Kenneth H. y Davis, Clive M. (1978). Effects of fear-arousing communications and topic importance on attitude change. Joumal of Social Psychology. № 104, pp. 81-85. doi: 10.1080/00224545.1978.9924040

Boster, Franklin J. y Mongeau, Paul A. (1984). Fear-arousing persuasive messages. En Bostrom, Robert N. (ed.). Communication yearbook 8. Beverly Hills: Sage, pp. 330-375.

Burgoon, Michael; Jones, S.B. y Stewart, D. (1975). Toward a message-centered theory of persuasion: three empirical investigations of language intensity. Human Communication Research. № 1, pp. 240-256. doi: 10.1111/j.1468-2958.1975.tb00271.x

CebriàAndreu, J.; Palma Sevillano, C.; Gutiérrez Blanch, I.; Ferrer Ventura, M.; Ger Cabero, S. y Doménech Cortés, M. (2005). Estudio del grado de aprensión social en usuarios de atención primaria: su relación con la ansiedad. Atención Primaria. Vol. 36, nº 5, pp. 254-260.

Cho, Hyunyi y Witte, Kim (2004). A review of fear appeal effects. En Gass, Robert H. y Seiter, John S. (eds.). Perspectives on persuasion, social influence, and compliance gaining. Boston: Pearson, pp. 223238.

Collins, Sandra D. (2009). Persuasion. Mason: Cengage Leaming. 
Dillard, James P. (1994). Rethinking the study of fear appeals. Communication Theory. № 4, noviembre, pp. 295-323. doi: 10.1111/j.1468-2885.1994.tb00094.x

Dillard, James P. y Anderson, Jason W. (2004). The role of fear in persuasión. Psychology \& Marketing. № 21, pp. 909-926. doi: 10.1002/mar.20041

González Herrero, Adolfo (1998). Marketing preventivo: la comunicación de crisis en la empresa. Barcelona: Bosch.

Gordon, George N. (1971). Persuasion: the theory and practice of manipulative communication. Nueva York: Hastings House.

Hansen, R. y Scott, C.A. (1976). Comments on attribution theory and advertiser credibility. Journal of Marketing Research. Vol. 13, pp. 193-207. doi: 10.2307/3150858

Henley, N. y Donovan, R.J. (2003). Young people's response to death threat appeals: do they really feel immortal? Health Education Research. Vol. 18, no 1, pp. 1-14. doi: 10.1093/her/18.1.1

Hewgill, Murray A. y Miller, Gerald R. (1965). Source credibility and response to fear-arousing communication. Speech Monographs. № 32, pp. 95-101.

Higbee, Kenneth L. (1969). Fifteen years of fear arousal: research on threat appeals 1953-1968. Psychological Bulletin. Vol. 72, nº 6, pp. 426-444. doi: 10.1037/h0028430

Hovland, Carl I.; Janis, Irving L. y Kelley, Harold H. (1953). Communication and persuasion. New Haven: Yale University Press.

Janis, Irving L. (1967). Effects of fear arousal on attitude change: recent developments in theory and experimental research. En Berkowitz, Leonard (ed.). Advances in experimental social psychology. Nueva York: Academic Press. Vol. 3, pp. 166-225.

Janis, Irving L. y Feshbach, Seymour (1953). Effects of fear arousing communications. Journal of Abnormal and Social Psychology. № 48, pp. 78-92. doi: 10.1037/h0060732

Leventhal, Herbert (1970). Findings and theory in the study of fear communications. En Berkowitz, Leonard (ed.). Advances in experimental social psychology. Nueva York: Academic Press. Vol. 5, pp. 119-186.

López-Quesada, M. (2003). ¡Estamos en crisis! Madrid: Dossat.

López Quintás, Alfonso (1998). La revolución oculta: manipulación del lenguaje y subversión de valores. Madrid: PPC.

Losada Díaz, José Carlos (2010). Comunicación en la gestión de crisis. Barcelona: UOC.

Marín, Francisco (2005). Gestión técnica y de la comunicación en situaciones especiales: crisis, emergencias y negociación. Madrid: Fragua.

Marín, Francisco (2009). Comunicación de crisis. Madrid: Acción Empresarial.

Martínez Segura, Pablo (2006). Crisis sanitarias y medios de comunicación. Revista de Administración Sanitaria. Vol. 4, n 3, pp. 437-438.

Martínez Solana, Yolanda (2004). La crisis de las 'vacas locas' en España: la necesidad de una información sanitaria responsable. Estudios sobre el Mensaje Periodístico. № 10, pp. 139-158. 
McGuire, William J. (1964). Inducing resistance to persuasion: some contemporary approaches. En Berkowitz, Leonard (ed.). Advances in experimental social psychology. Nueva York: Academic Press. Vol. 1, pp. 191-229.

McGuire, William J. (1968). Personality and attitude change: an information processing theory. En Greenwald, Anthony G.; Brock, Timothy C. y Ostrom, Thomas M. (eds.). Psychological foundations of attitudes. Nueva York: Academic Press, pp. 171-196.

McGuire, William J. (1969). The nature of attitudes and attitude change. En Lindzey, Gardner y Aronson, Elliot (eds.). Handbook of social psychology. Reading: Addison-Wesley Publishing Co. Vol. 3, pp. 136-314.

McGuire, William J. (1973). Persuasion, resistance and attitude change. En Pool, Ithiel de Sola; Frey, Frederick W.; Schramm, Wilbur y Parker, Edwin B. (eds.). Handbook of communication. Chicago: Rand Mc Nally, pp. 253-289.

Mongeau, Paul A. (1998). Another look at fear-arousing persuasive appeals. En Allen, Mike y Preiss, Raymond W. (eds.). Persuasion: advances through meta-analysis. Cresskill: Hampton Press, pp. 53-68.

Pratkanis, Anthony y Aronson, Elliot (1994). La era de la propaganda: uso y abuso de la persuasión. Barcelona: Paidós.

Quinn, Valerie; Meenaghan, Tony y Brannick, Teresa (1992). Fear appeals: segmentation is the way to go. Intemational Joumal of Advertising. Vol. 11, $\mathrm{n}^{\circ}$ 4, pp. 355-367.

Rodríguez Andrés, Roberto y Ureña, Daniel (2008). Los gabinetes de prensa de instituciones políticas como configuradores de la agenda mediática. En Jurado Martín, Montserrat y Carvajal Prieto, Miguel (eds.). La arquitectura de la información. Murcia: DM, pp. 177-186.

Rogers, R.W. (1975). A protection motivation theory of fear appeals and attitude change. Journal of Psychology. № 91, pp. 93-114. doi: 10.1080/00223980.1975.9915803

Rogers, R.W. (1983). Cognitive and physiological processes in fear appeals and attitude change: a revised theory of protection motivation. En Cacioppo, John T. y Petty, Richard E. (eds.). Social psychophysiology: a sourcebook. Nueva York: Guilford Press, pp. 153-176.

Rogers, R.W. (1985). Attitude change and information integration in fear appeals. Psychological Reports, № 56, pp. 179-182. doi: 10.2466/pr0.1985.56.1.179

Rogers, R.W. y Prentice-Dunn, S. (1997). Protection motivation theory. En Gochman, D.S. (ed.). Handbook of Health Behavior Research. Nueva York: Plenum Press. Vol. 1, pp. 113-132.

Ross, Raymond S. (1978). Persuasión: comunicación y relaciones interpersonales. México: Editorial Trillas. Rotfeld, Herbert J. (1988). Fear appeals and persuasion: assumptions and errors in advertising research. Current Issues \& Research in Advertising. Vol. 11, n 1, pp. 21-40.

Salcedo Fernández, Antonio (2008). Anatomía de la persuasión. Madrid: Esic.

Saura, Pilar (2005). La gestión y la comunicación de crisis en el sector de alimentación y bebidas. Madrid: Universidad Pontificia de Comillas.

Seeger, Matthew W. y Sellnow, Timothy L. (2007). Crisis communication and the public health. Cresskill: Hampton Press. 
Sutton, Stephen R. (1982). Fear-arousing communications: a critical examination of theory and research. En Eiser, J. Richard (ed.). Social psychology and behavioural medicine. Londres: Wiley, pp. 303-337.

Stemthal, B. y Craig, C.S. (1974). Fear appeals: revised and revisited. Journal of Consumer Research. Vol. 1, no 3, pp. 22-34. doi: 10.1086/208597

Stemthal, B.; Phillips, L.W. y Dholakia, R. (1978). The persuasive effect of source credibility: a situational analysis. Public Opinion Quarterly. Vol. 42, nº 3, p. 285-314. doi: 10.1086/268454

Stiff, James B. (1994). Persuasive communication. Nueva York: The Guilford Press.

Sutton, Stephen R. (1982). Fear-arousing communications: a critical examination of theory and research. En Eiser, J. R. (ed.). Social Psychology and Behavioral Medicine. Chichester: Wiley, pp. 303-337.

Valera, Carmen (2008). Cómo gestionar el miedo y limitar sus consecuencias. Revista de Comunicación, $\mathrm{N}^{\circ} 6$, pp. 50-52.

Wiener, J.L. y Mowen, J.C. (1986). Source credibility: on the independent effects of trust and expertise. Advances in Consumer Research. Vol. 13, n 1, pp. 306-310.

Witte, Kim (1992). Putting the fear back into fear appeals: the extended parallel process model. Communication Monographs. № 59, diciembre, pp. 329-349. doi: 10.1080/03637759209376276

Witte, Kim (1994). Fear control and danger control: an empirical test of the extended parallel process model. Communication Monographs. Vol. 61, pp. 113-134. doi: 10.1080/03637759409376328

Witte, Kim (1998). Fear as motivator, fear as inhibitor: using the extended parallel process model to explain fear appeals successes and failures. En Andersen, P.A. y Guerrero, L.K. (eds.). Handbook of communication and emotion: research, theory, applications, and contexts. San Diego: Academic Press, pp. 423-450.

Witte, Kim y Allen, Mike (2000). A meta-analysis of fear appeals: implications for effective public health campaigns. Health Education \& Behavior. Vol. 27, nº 5, pp. 591-615. doi: 10.1177/109019810002700506 